\title{
Using QALYs in telehealth evaluations: a systematic review of methodology and transparency
}

\author{
Trine S Bergmo
}

\begin{abstract}
Background: The quality-adjusted life-year (QALY) is a recognised outcome measure in health economic evaluations. QALY incorporates individual preferences and identifies health gains by combining mortality and morbidity into one single index number. A literature review was conducted to examine and discuss the use of QALYs to measure outcomes in telehealth evaluations.

Methods: Evaluations were identified via a literature search in all relevant databases. Only economic evaluations measuring both costs and QALYs using primary patient level data of two or more alternatives were included.

Results: A total of 17 economic evaluations estimating QALYs were identified. All evaluations used validated generic health related-quality of life (HRQoL) instruments to describe health states. They used accepted methods for transforming the quality scores into utility values. The methodology used varied between the evaluations. The evaluations used four different preference measures (EQ-5D, SF-6D, QWB and HUI3), and utility scores were elicited from the general population. Most studies reported the methodology used in calculating QALYs. The evaluations were less transparent in reporting utility weights at different time points and variability around utilities and QALYs. Few made adjustments for differences in baseline utilities. The QALYs gained in the reviewed evaluations varied from 0.001 to 0.118 in implying a small but positive effect of telehealth intervention on patient's health. The evaluations reported mixed cost-effectiveness results.
\end{abstract}

Conclusion: The use of QALYs in telehealth evaluations has increased over the last few years. Different methodologies and utility measures have been used to calculate QALYs. A more harmonised methodology and utility measure is needed to ensure comparability across telehealth evaluations.

Keywords: Telehealth, Telemedicine, Videoconferencing, Remote consultations, E-Health, Health-related quality of life, Quality-adjusted life-years, Cost-utility analysis

\section{Background}

The outcomes of telehealth interventions are not easily defined, identified or measured [1]. Effectiveness has been measured in a number of different ways, ranging from the impact on processes to the final outcomes. In economic analyses, the measured outcomes have been diagnostic accuracy, avoided travel and reduced hospitalisation. Disease-specific scale measures such as blood glucose levels, reduction in wound size, anxiety and pain levels and quality of life measures have also been used [2-4]. Disease-specific measures are acceptable for assessing technical efficiency, i.e., how to produce a

Correspondence: trine.bergmo@telemed.no

Norwegian Centre for Telemedicine and Integrated Care, University Hospital of North Norway, N-9038 Tromsø, Norway given level of health outcome for the least cost. For example, diabetes-specific measures can be used to assess whether a new technological device is more effective than existing technology in reducing and stabilising blood glucose levels. Disease-specific and quality of life measures do not include the duration of the improvement, nor can they be used to compare costs and outcomes across disease areas. It can be difficult to interpret cost-effectiveness in terms of a specific cost per reduction in blood glucose level. Furthermore, scores obtained from quality of life questionnaires such as the SF-36 Health Survey cannot be used directly in economic evaluations because the scores do not rank health states according to patients' preferences and are not measured on a death-full health scale. 
Consistency in the outcome measures has important implications for the usefulness of cost-effectiveness results in decision making [5]. To aid resource allocation, we need a common metric that enables the comparison of different kinds of improvements across disease areas and can be compared to the costs in a meaningful way. Quality-adjusted life-year (QALY) is one such measure. QALYs were developed to compare health gains; they are recognised as the primary metric to measure health status in economic evaluation [6-9]. QALYs include mortality and morbidity in one single measure [10]. QALYs are the years lived weighted by the quality of life in that time [8]. Comparing costs and QALYs is also known as cost-utility analysis (CUA). The cost-utility framework is constrained to production decisions, i.e., where a decision maker considers how to best allocate an existing budget. In this situation, the objective is often to establish which alternative maximises the health outcome for a given cost. CUA implicitly assumes that one of the programmes will be undertaken regardless of its net benefit [9]. If the decision maker is considering whether it is worthwhile to achieve a particular goal or expand the budget, a broader cost-benefit analysis is needed. Costbenefit analysis measures all consequences in a monetary unit and addresses the right mixture of healthcare programmes to maximise the health of a society [11].

The literature contains a large number of telehealth reviews [12]. Most economic evaluations in telehealth to date have used a cost-consequence framework or cost-minimisation analysis (CMA) [2,3,13]. A costconsequence framework lists all benefits alongside costs without synthesising costs and benefits, which can make it difficult to decide whether the intervention produces good value for money. CMA assumes no difference in outcome and compares only the costs. CMA is generally not viewed an appropriate method of analysis in prospective evaluations [14]. However, the purpose of telehealth might be to provide consultations or episodes of care. If the objective is to establish the least costly mode of delivering specific health services, CMA can be a useful framework.

Few economic evaluations of telehealth interventions have measured health gains in QALYs [4]. A review from 2009 found four evaluations measuring QALYs [3]. A more recent review found seven [2]. None of these previous reviews have examined and discussed the way in which QALYs have been calculated and reported in the literature. The estimation of QALYs in telehealth evaluations should be methodologically appropriate, and its reporting should be transparent.

The aim of this paper is to review and discuss the use of QALYs in economic evaluations of telehealth interventions. In particular, this work examines the ways in which health utility data are used to generate QALYs. It also assesses the transparency of the methods used. This paper contributes to the literature in the following ways: (1) it provides an overview of telehealth studies using QALYs within a cost-effectiveness framework, (2) it reports on the methods used in calculating QALYs, (3) it addresses the transparency of the QALY estimation and reporting of results and (4) it discusses the use of QALYs in telehealth evaluations.

\section{Estimating QALYs}

QALYs are estimated in three steps. The first step is to collect preference-based health-related quality of life (HR-QoL) measures to develop health states. HR-QoL measures can be obtained using generic pre-scored descriptive classification systems. One of the most commonly used descriptive systems is the EuroQol-5D (EQ-5D), which was developed by the EuroQol group [15]. EQ-5D is a recognised tool to describe different health states and is recommended in economic evaluation guidelines $[9,10,16]$. The EQ-5D has five attributes: mobility, self-care, usual activities, pain/discomfort and anxiety/depression, each of which has three levels. Another descriptive system used to derive HRQoL measures is the SF-6D which can be extracted from SF-36 and SF-12 Health Surveys. Brazier and his colleagues simplified these into six dimensions, obtained preference scores and estimated preference weights from the general population using the standard gamble technique $[17,18]$. The six dimensions are physical functioning, role limitation, social functioning, pain, mental health and vitality, each of which has four to six levels. Other generic prescored health state classification systems are the Health Utility Index (HUI) [9], Quality of Well-Being (QWB) [19], Assessment of Quality of Life (AQoL) [20] and 15D [21].

The second step is to attach preference weights (values or utilities) to the different HRQoL measures defined by the descriptive systems. This process involves weighting the relative importance of the different aspects in the questionnaire using preference scores [5]. These are derived from the general population and fall on a scale from 1 (full health) to 0 (death). It is possible to be in a health state worse than death with a negative quality index. The National Institute for Health and Clinical Excellence (NICE) in the United Kingdom recommends a set of values estimated from 3,000 members of the UK population using the time trade-off technique [22]. Other countries have estimated similar country-specific health state utility values [23]. An alternative approach is to ask the patients directly in interviews to describe and value their health status using complex techniques such as time trade-off (a choice between quality of life and longevity of life) or standard gamble (a choice between a certain outcome and a gamble on either better or worse health) [24]. These techniques are more time consuming and expensive than using the population based utility weights. 
The third step is to calculate the QALYs gained by including time. This involves multiplying the quality weights for the health states developed in step two with the duration of each health state experienced by the patients. For example, one year in full health is one QALY. Four years in a 0.5 quality state is two QALYs. The general formula for a QALY gain can be written as follows:

$$
\text { QALY gain }=\mathrm{Q}_{1} \times \mathrm{T}_{1}-\mathrm{Q}_{0} \times \mathrm{T}_{0}
$$

where $\mathrm{Q}_{1} \times \mathrm{T}_{1}$ refers to the quality weight $\mathrm{Q}_{1}$ multiplied by the expected duration $\mathrm{T}_{1}$ (expected health status) with intervention or treatment. $\mathrm{Q}_{0} \times \mathrm{T}_{0}$ refers to the quality weight $\mathrm{Q}_{0}$ multiplied by the expected duration $\mathrm{T}_{0}$ for the usual care or no-treatment alternative.

When costs and QALYs have been measured and valued, the next step is to compare the costs and QALYs of the new intervention to those of the alternative or existing technology on an ordinal level [10]. If the new intervention costs less and generates more QALYs than the existing alternative, then the new technology is cost effective and no further analysis is needed. Similarly, if the services generate less benefit at increased cost, then no further analysis is needed. If the new intervention costs more and is more effective, a more rigorous economic evaluation is needed. In the latter situation, it is necessary to calculate the cost per QALY or the incremental cost-effectiveness ratio (ICER). ICER establishes how much more the new technology costs and how much more effective it is compared to the alternative.

\section{Methods}

The review was limited to economic evaluations of the use of any type of information and communication technology to examine, treat, monitor, follow up or care for patients over a distance, where the outcomes have been measured in QALYs. The interventions evaluated used telemonitoring, store-and-forward transmissions of data, video links, email consultations or structured telephone support. Webbased motivational self-help interventions without any communication with health providers were excluded.

The search was limited to articles written in English and published in peer-reviewed journals between 1990 and 2012. The articles included were economic evaluations, i.e., they undertook a comparative analysis of both costs as resource use and outcomes in the form of QALYs of at least two alternatives. Only cost-effectiveness analyses using primary patient-level data were included. Evaluations using models to extrapolate primary data beyond the trial period were also included. Evaluations synthesising secondary data from a number of different sources into a decision modelling framework, protocol papers describing ongoing evaluations, and evaluations using scores from the descriptive systems or utility data without calculating QALYs were excluded.

The search strategy included two main search terms:

1. ("telemedicine" [MeSH Terms] OR "telehealth" [All Fields] OR telemonitoring [All Fields] OR telecare [All Fields] OR "remote consultation" [MeSH Terms] OR teleconsultations [All Fields] OR e-health [All Fields] OR "videoconferencing" [MeSH Terms] OR "telephone" [MeSH Terms] OR Internet- based [All Fields] OR "Internet" [MeSH Terms]) AND

2. ("quality-adjusted life-years" [MeSH Terms] OR "qalys" [All Fields] OR cost-utility [All Fields])

The electronic literature databases PubMed, PsycInfo and CINAHL were searched using a combination of the search strategy above. The National Health Service Economic Evaluation Database (NSH EED) was searched using "telemedicine" OR "telehealth" OR "videoconferencing" OR "telephone". The two main journals in the telemedicine field, Journal of Telemedicine and Telecare and Telemedicine Journal and E-health, were searched electronically using only "QALYs" or "cost-utility".

The selection of relevant publications was based on information found in the abstracts. Full-text articles were retrieved when the abstract indicated analyses of both costs and QALYs. Full-text articles were also retrieved for closer inspection if the abstract did not provide a clear indication of the content. All abstracts and full-text articles were read by the author. Figure 1 shows a flow diagram mapping the number of studies identified, included and excluded, as well as the reasons for exclusion.

Information divided into three main categories was extracted and used to assess the reviewed articles. These main categories were as follows: (1) general characteristics of the evaluations, (2) methodology and transparency of the QALY estimation and (3) reporting of results, including handling of uncertainty. Details extracted from the evaluations were as follows: type of intervention, technology used, sample size, effectiveness data, utility values, data collection intervals, costing method, methods for handling uncertainty, how the difference in costs and QALYs was reported, whether incremental cost per QALY was calculated, and key findings.

\section{Results}

\section{General characteristics}

The search strategy described above identified 17 economic evaluations of telehealth interventions. Table 1 provides a summary of the evaluations included in the review. Most evaluations analysed structured telephone support and monitoring as part of a remote follow-up regimen 


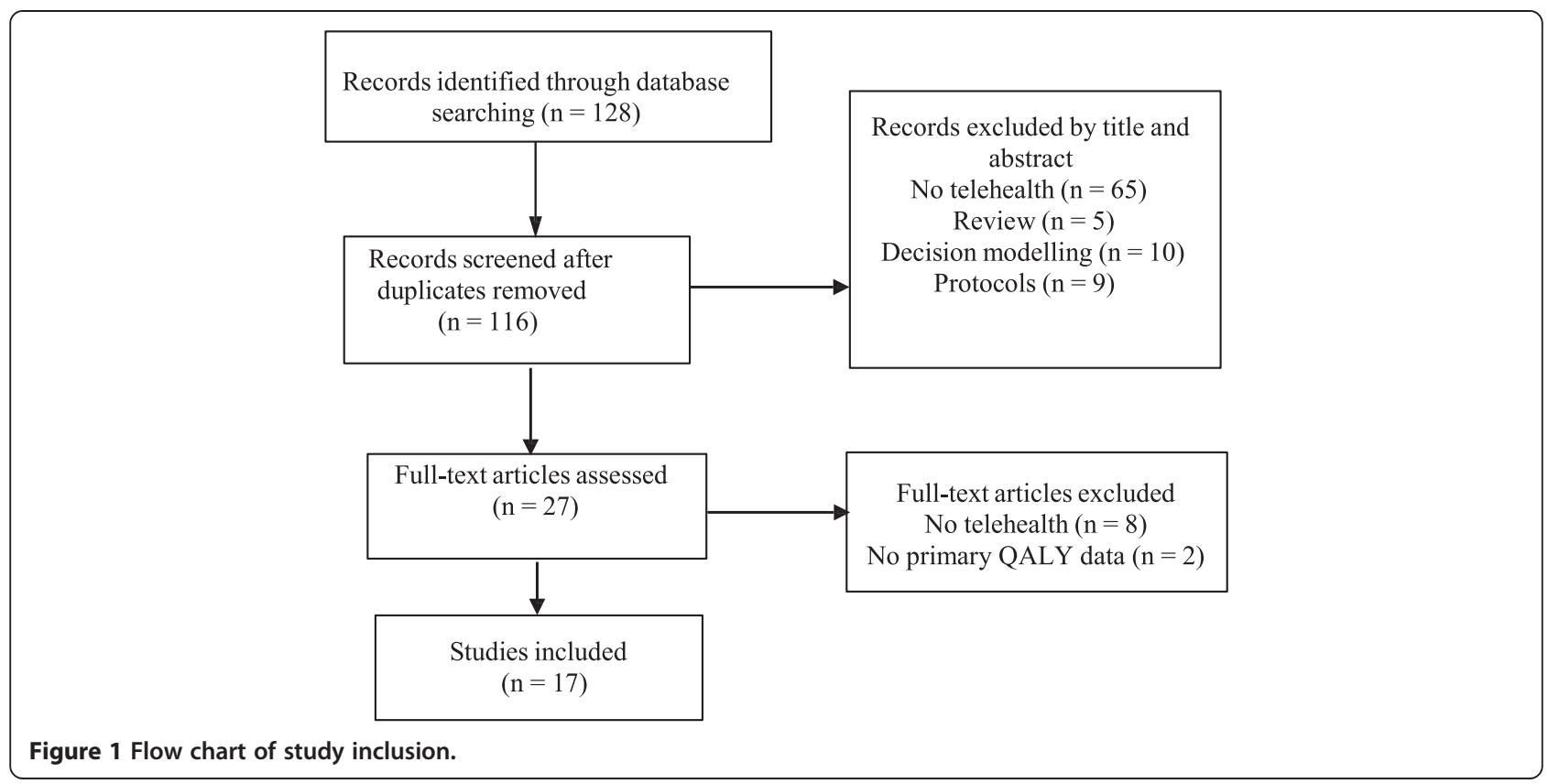

after treatment. Several evaluations analysed a combination of Internet interventions and telephone follow-up. Two evaluations included video link as part of the telehealth follow-up intervention. The papers were published between 2007 and 2012. Most papers were published over the last two years (see Table 2). Seven originated from the Netherlands, five from the United States, two from Australia, two from the United Kingdom and one from Sweden.

All but one evaluation were conducted alongside prospective randomised controlled trials (RCTs). The one exception analysed home telehealth using a retrospective prepost evaluation design. It was the only evaluation with costeffectiveness as a primary outcome measure [25]. Another evaluation used HRQoL as a primary outcome and the EQ$5 \mathrm{D}$ as the basis for sample size calculation [26]. In the remaining evaluations, costs and QALYs were secondary outcomes. Sample sizes varied from 48 to 1600 . Only four evaluations had less than 200 participants [27-30]. Two evaluations (by the same author) used modelling: one to extrapolate results over ten years [31], and another to map the progress of the participants during the study period [32].

Seven evaluations took a societal perspective on costs and included health care costs, patient costs and production loss. Six evaluations included only health care costs, one included health provider and patient costs and two included only intervention costs. Most evaluations $(60 \%)$ did a comprehensive cost analysis and included all costs relevant to the reported perspective (see Table 1).

\section{QALY estimation}

All the reviewed evaluations used a validated HRQoL instrument to describe the health states. Two thirds of the evaluations used the EQ-5D and one third used the SF6D. One evaluation used both EQ-5D and SF-6D and reported results only for EQ-5D utilities [29]. Another evaluation used the HUI3 in combination with the EQ5D and found more QALYs gained using HUI3 [33]. Another used the QWB in combination with the SF-6D and found a significant improvement only for the SF-6D values [34] (see Table 3). No direct valuation method was used to obtain health state utilities. All the reviewed evaluations collected HRQoL data from patients participating in the actual intervention study. Data were collected at baseline and at regular intervals during the study period. Only one study did not include information about when data had been collected [35]. The study periods varied from 10 weeks to 24 months.

Most evaluations reported the method used to transform the scores from the descriptive systems into utility values. Four used the preference score collected from a sample of the UK population developed by Dolan [36]. Three evaluations used a Dutch preference score developed by Lamers [37,38]. One evaluation mapped the EQ-5D utilities from the SF-12 using an algorithm described by Gray and his colleagues [39]. The algorithm by Brazier et al. was used for SF-6D $[18,40]$. To transform the QWB into utility values, categorical rating scale values from a community sample and a multi-attribute utility model were used [19]. Hebert et al. [33] estimated QALYs by translating the SF-12 physical and mental score into HUI3 and EQ-5D using a method that has been validated among the AfricanAmerican patients [41]. Only two evaluations did not report the method used to derive utility values $[27,30]$. Three evaluations did not report utility estimates $[25,35,42]$. 
Table 1 Summary of the economic evaluations

\begin{tabular}{|c|c|c|c|c|c|c|}
\hline Article & $\begin{array}{l}\text { Intervention } \\
\text { sample size (N) }\end{array}$ & Utility data & Utility intervals & Costing & $\begin{array}{l}\text { Difference in } \\
\text { costs and QALYs }\end{array}$ & $\begin{array}{l}\text { Key findings (ICER and cost } \\
\text { effectiveness results) }\end{array}$ \\
\hline Barnett 2007 [25] USA & $\begin{array}{l}\text { Messaging and video } \\
\text { for diabetes } N=370\end{array}$ & SF-6D (SF-36) & $\begin{array}{l}\text { Baseline and } \\
12 \text { months }\end{array}$ & $\begin{array}{l}\text { Health provider, no cost } \\
\text { information provided }\end{array}$ & $\begin{array}{l}\text { Difference in QALYS or } \\
\text { costs not reported }\end{array}$ & $\begin{array}{l}\$ 60,940 \text { per QALY and cost effective, } 23 \% \text { cost } \\
\text { effective at } \$ 200000,37 \% \text { at } \$ 100,000 \text { and } \\
42 \% \text { at a threshold of } \$ 200,000\end{array}$ \\
\hline $\begin{array}{l}\text { Blankers } 2012 \text { [28] } \\
\text { Netherland }\end{array}$ & $\begin{array}{l}\text { Internet therapy for } \\
\text { harmful alcohol } \\
\text { use } N=136\end{array}$ & EQ-5D & $\begin{array}{l}\text { Baseline and } \\
6 \text { months }\end{array}$ & $\begin{array}{l}\text { Health provider and } \\
\text { societal, comprehensive }\end{array}$ & $\begin{array}{l}0.06 \text { QALYs gained, } \\
\text { Cl/p not reported, } \\
\text { increased costs (NS) }\end{array}$ & $\begin{array}{l}\text { Median cost per QALY } € 14,710 \text {. The } \\
\text { intervention had a } 60 \% \text { likelihood of } \\
\text { being cost effective at threshold } € 20,000\end{array}$ \\
\hline Franzen 2009 [26] Sweden & $\begin{array}{l}\text { Telephone follow-up } \\
\text { for injured road } \\
\text { users } N=510\end{array}$ & EQ-5D & $\begin{array}{l}\text { Baseline, }(3)^{\S} \text {, } \\
\text { and } 6 \text { months }\end{array}$ & $\begin{array}{l}\text { Intervention costs for } \\
\text { the health system }\end{array}$ & $\begin{array}{l}0.01 \text { QALYs gained, } \\
\text { increased costs, } \\
\text { Cl/p not reported }\end{array}$ & 42,500 SEK per QALY and cost effective \\
\hline Graves 2009 [31] Australia & $\begin{array}{l}\text { Telephone intervention } \\
\text { for physical activity } \\
N=431\end{array}$ & SF-6D (SF-36) & $\begin{array}{l}\text { Baseline, } 4 \text { and } \\
12 \text { months }\end{array}$ & $\begin{array}{l}\text { Health provider, } \\
\text { comprehensive }\end{array}$ & $\begin{array}{l}\text { QALYs gained not explicitly } \\
\text { reported on individual level*, } \\
\text { increased costs }\end{array}$ & $\begin{array}{l}\text { Telehealth vs usual care } \$ 78,489 \text { per QALY } \\
\text { and not cost effective. Telehealth vs real } \\
\text { control (no follow up) } \$ 29375 \text { per QALY } \\
\text { and cost-effective }\end{array}$ \\
\hline Graves 2009 [32] Australia & $\begin{array}{l}\text { Telephone support to } \\
\text { prevent re-hospitalisation } \\
N=122\end{array}$ & $\begin{array}{l}\text { EQ-5D mapped } \\
\text { from SF-12 }\end{array}$ & $\begin{array}{l}\text { Baseline } 4,12, \\
\text { and } 24 \text { weeks }\end{array}$ & $\begin{array}{l}\text { Health provider, } \\
\text { comprehensive }\end{array}$ & $\begin{array}{l}0.118 \text { QALYs gained }(S) \text {, } \\
\text { reduced costs NS }\end{array}$ & $\begin{array}{l}\text { NMB } \$ 7,907.100 \% \text { probability of increased } \\
\text { QALYs and } 64 \% \text { probability of reduced costs }\end{array}$ \\
\hline Handley 2008 [47] USA & $\begin{array}{l}\text { Telephone follow-up in } \\
\text { diabetes care } \mathrm{N}=226\end{array}$ & SF-6D (SF-12) & $\begin{array}{l}\text { Baseline and } \\
12 \text { months }\end{array}$ & $\begin{array}{l}\text { Intervention costs for } \\
\text { the health provider }\end{array}$ & $\begin{array}{l}0.012 \text { QALYs gained, } \\
\text { increased costs, } \\
\mathrm{Cl} / \mathrm{p} \text { not reported }\end{array}$ & $\begin{array}{l}\$ 65,167 \text { per QALY gained and within } \\
\text { accepted cost effective range } \\
\text { without specification }\end{array}$ \\
\hline Herbert 2008 [33] USA & $\begin{array}{l}\text { Telephone follow-up in } \\
\text { heart failure } \mathrm{N}=406\end{array}$ & $\begin{array}{l}\text { HUI3 and EQ-5D } \\
\text { mapped from SF-12 }\end{array}$ & $\begin{array}{l}\text { Baseline, 3, 6, } 9 \\
\text { and } 12 \text { months }\end{array}$ & $\begin{array}{l}\text { Societal and payer, } \\
\text { comprehensive }\end{array}$ & $\begin{array}{l}0.0497 \text { QALYs gained (HUI3) } \\
0.0430 \text { QALYs gained (EQ-5D) } \\
\text { (S), no difference in costs }\end{array}$ & $\begin{array}{l}\$ 17,543(\mathrm{EQ}-5 \mathrm{D}) \text { and, } \$ 15,169(\mathrm{HUI}) \text { with } \\
\text { a } 64 \% \text { and } 77 \% \text { probabilities of } \\
\text { cost-effectiveness }\end{array}$ \\
\hline $\begin{array}{l}\text { Kimman } 2011 \text { [42] } \\
\text { Netherland }\end{array}$ & $\begin{array}{l}\text { Telephone follow-up } \\
\text { after breast cancer } \\
\text { treatment } N=299\end{array}$ & EQ-5D & $\begin{array}{l}\text { Baseline, 3, 6, } \\
\text { and } 12 \text { months }\end{array}$ & Societal, comprehensive & $\begin{array}{l}\text { QALY gained not reported, } \\
\text { increased costs }\end{array}$ & $\begin{array}{l}\text { Telephone the preferred strategy. At a } \\
\text { threshold of } € 80,000,62 \% \text { probability } \\
\text { of being cost effective }\end{array}$ \\
\hline Moss-Morris 2012 [27] UK & $\begin{array}{l}\text { Internet and telephone } \\
\text { follow-up for fatigue } \\
N=40\end{array}$ & $E Q-5 D$ & $\begin{array}{l}\text { Baseline and } \\
10 \text { weeks }\end{array}$ & Health provider & $\begin{array}{l}0.015 \text { QALYs gained }(S) \text {, } \\
\text { no difference in costs }\end{array}$ & The intervention is cost-effective \\
\hline $\begin{array}{l}\text { Neelemaat } 2012 \text { [43] } \\
\text { Netherland }\end{array}$ & $\begin{array}{l}\text { Telephone support } \\
\text { to malnourished } \\
\text { elderly } N=210\end{array}$ & $E Q-5 D$ & $\begin{array}{l}\text { Baseline and } \\
3 \text { months }\end{array}$ & Societal, comprehensive & $\begin{array}{l}0.02 \text { QALYs gained } \\
\text { (NS), increased costs }\end{array}$ & $\begin{array}{l}€ 26,962 \text { per QALY. For thresholds at } \\
€ 20000 \text { the probability of cost } \\
\text { effectiveness is } 50 \%\end{array}$ \\
\hline Pyne 2010 [34] USA & $\begin{array}{l}\text { Video-link and telephone } \\
\text { support for depression } \\
N=335\end{array}$ & SF-6D (SF-12) QWB & $\begin{array}{l}\text { Baseline, } 6 \text { and } \\
12 \text { months }\end{array}$ & $\begin{array}{l}\text { Health provider and } \\
\text { patient, comprehensive }\end{array}$ & $\begin{array}{l}\text { QWB } 0.015 \text { QALYs gained } \\
\text { (NS), SF-6D 0.018 QALYs } \\
\text { gained (S), increased costs }\end{array}$ & $\begin{array}{l}\$ 85,634 \text { per QALY (health provider), } \\
\$ 132,175 \text { per QALY (incl. patient } \\
\text { costs) Not cost-effective }\end{array}$ \\
\hline Smith 2008 [35] USA & $\begin{array}{l}\text { Monitoring in heart } \\
\text { failure } N=1069\end{array}$ & SF-6D (SF-36) & Not reported & Health provider & $\begin{array}{l}\text { Difference in QALYs not } \\
\text { reported, increased costs }\end{array}$ & $\$ 146,870$ per QALY, Not cost-effective \\
\hline $\begin{array}{l}\text { van der Meer } 2011 \\
\text { [45] Netherland }\end{array}$ & $\begin{array}{l}\text { Internet intervention } \\
\text { for asthma } N=200\end{array}$ & EQ-5D & $\begin{array}{l}\text { Baseline, 3, and } \\
12 \text { months }\end{array}$ & Societal, comprehensive & $\begin{array}{l}0.024 \text { QALYs gained (NS), } \\
\text { no difference in costs }\end{array}$ & $\begin{array}{l}\$ 26,700 \text { per QALY, } 62 \% \text { probability of } \\
\text { cost-effective at threshold of } \$ 50,000\end{array}$ \\
\hline $\begin{array}{l}\text { van Keulen } 2010 \\
\text { [44] Netherland }\end{array}$ & $\begin{array}{l}\text { Intervention to motivate } \\
\text { patients with hypertension } \\
N=1629\end{array}$ & SF-6D (SF-36) & $\begin{array}{l}\text { Baseline and } \\
7 \text { months }\end{array}$ & $\begin{array}{l}\text { Intervention cost } \\
\text { and time costs for } \\
\text { the participants }\end{array}$ & $\begin{array}{l}0.02 \text { QALYs gained (S) } \\
\text { Telephone most costly }\end{array}$ & $\begin{array}{l}\text { Control group most cost effective } \\
\text { for ceiling ratios lower than } \\
\$ 2851 \text { per QALY }\end{array}$ \\
\hline
\end{tabular}


Table 1 Summary of the economic evaluations (Continued)

\begin{tabular}{|c|c|c|c|c|c|c|}
\hline $\begin{array}{l}\text { Van Wier } 2012 \\
\text { [46] Netherland }\end{array}$ & $\begin{array}{l}\text { Telephone and e-mail } \\
\text { advice for overweight } \\
\mathrm{N}=1386\end{array}$ & EQ-5D & $\begin{array}{l}\text { Baseline, } 6, \\
12,18 \text { and } \\
24 \text { months }\end{array}$ & Societal, comprehensive & $\begin{array}{l}\text { Phone } 0.001 \text { and Internet } 0.01 \\
\text { QALYs gained NS, no } \\
\text { difference in costs }\end{array}$ & $\begin{array}{l}\text { Internet } € 1337 \text { per QALY and not } \\
\text { cost-effective. Phone } € 245,000 \text { per } \\
\text { QALY. Cost effective at WTP } € 20,000 \text {; } \\
8 \% \text { for Phone, } 60 \% \text { for Internet and } \\
32 \% \text { for control }\end{array}$ \\
\hline $\begin{array}{l}\text { Willems } 2007 \\
\text { [29] Netherland }\end{array}$ & $\begin{array}{l}\text { Home monitoring of } \\
\text { asthmatics } N=109\end{array}$ & $\begin{array}{l}\text { SF-6D (SF-36) } \\
\text { EQ-5D }\end{array}$ & $\begin{array}{l}\text { Baseline, } 4,8 \\
\text { and } 12 \text { months }\end{array}$ & Societal, comprehensive & $\begin{array}{l}\text { Adults } 0.03 \text { and children } \\
0.01 \text { QALYs gained (EQ-5D) } \\
\text { (S), increased costs (NS) }\end{array}$ & $\begin{array}{l}€ 31,000 \text { per QALY gained for adults } \\
\text { and } € 59 \text {, 000/QALY gained for the } \\
\text { children. Limited cost-effectiveness }\end{array}$ \\
\hline Yardly 2012 [30] UK & $\begin{array}{l}\text { Telephone support } \\
\text { for dizziness } N=236\end{array}$ & EQ-5D & $\begin{array}{l}\text { Baseline, } 3 \text { and } \\
12 \text { months }\end{array}$ & Health provider & $\begin{array}{l}0.022 \text { QALYs gained, Increased } \\
\text { costs, Cl/p not reported }\end{array}$ & $\begin{array}{l}£ 1363 \text { per QALY, Intervention } \\
\text { is cost effective }\end{array}$ \\
\hline
\end{tabular}

$\mathrm{NS}=$ not significant, $\mathrm{S}=$ significant, $\mathrm{Cl}=$ confidence interval, $\mathrm{p}=\mathrm{p}$-value, $\mathrm{NMB}=$ net monetary

${ }^{\mathrm{s}}$ Intervention group only. 
Table 2 Publication year

\begin{tabular}{ll}
\hline Year & No (\%) \\
\hline $2011-2012$ & $7(40)$ \\
$2009-2010$ & $5(30)$ \\
$2007-2008$ & $5(30)$ \\
\hline
\end{tabular}

Two third of the evaluations reported variability around the utility estimates. Half of the evaluations reported baseline and follow-up utility data separately. Five reported adjustment for differences in baseline utility data $[27,29,30,33,42]$. Most evaluations assumed linear utility changes over time. This was not clearly stated but could be deducted in most cases. QALYs were calculated using the change from baseline score $[27,29,31,43,44]$ or the area under the curve method [33,45,46]; in some cases the calculation was explicitly described $[28,42]$.

\section{Reporting of results}

The mean QALYs gained using telehealth services varied from 0.001 to 0.118 in the reviewed studies. Only six evaluations reported a significant QALY gain [27,29,32-34,44]. All six evaluations reported that the intervention was cost-effective. Three reported that the QALY gain was not significant $[43,45,46]$. Four evaluations did not report the confidence interval $(\mathrm{CI})$ or p-values $[26,28,30,47]$. Three evaluations did not report the difference in QALY at all $[25,35,42]$. In more than half of the evaluations, it was not possible to draw any conclusion about cost-effectiveness on an ordinal level. These evaluations reported small positive differences in QALYs at increased or similar costs but failed to report significance (see Table 1 for details). All, except one [27], calculated incremental cost per QALY or net monetary benefit (NMB).

Five evaluations stated a positive result in favour of telehealth based on thresholds alone [26,27,30,31,47]. Most evaluations calculated the probability of costeffectiveness within different willingness-to-pay thresholds. Six evaluations reported more than a $60 \%$ likelihood of being cost-effective. Two reported a 30\% - 50\% likelihood of reaching cost-effectiveness. Four reported that the telehealth service was not cost-effective.

Uncertainty due to sampling variation was handled by traditional statistical methods in most evaluations. Three analyses did not include any information on sampling

\section{Table 3 HRQoL instrument used to obtain QALYs}

\begin{tabular}{ll}
\hline HRQoL instruments & No. (\%) \\
\hline EQ-5D & $11(65)$ \\
SF-6D & $7(40)$ \\
QWB & $1(5)$ \\
HUI3 & $1(5)$ \\
\hline
\end{tabular}

Three evaluations used more than one instrument. variability in costs and outcomes [25,26,47]. Half of the evaluations (52\%) did report CI around the ICER or illustrated the variability in the cost-effectiveness plane. All except three evaluation [25-27], included cost-effectiveness acceptability curves (CEAC). Sensitivity analysis was undertaken in half of the evaluations.

\section{Discussion}

The use of QALYs is recognised as the main valuation technique to measure health outcomes $[7,9,24]$. Therefore, it is important to consider the appropriateness and transparency of the approaches and methodologies used to estimate QALYs in telehealth studies.

This review identified 17 economic evaluations that used QALYs to measure health outcomes. This seems like a modest number considering that cost-effectiveness is one of the main arguments for telehealth interventions. The number is also quite low, compared to the number of studies that use QALYs in other medical fields. Recent reviews found 33 QALY analyses in spine care [48], 81 studies that used QALYs to measure outcomes in screening programs [6] and 77 evaluations that used QALYs in the field of asthma [49]. However, this review shows that there has been an increased focus on measuring QALYs in telehealth evaluations over the last few years. All 17 studies were published after 2007, and almost half were published in 2011 and 2012.

Most evaluations analysed structured telephone consultations and monitoring of patients at home. More intensive and structured follow-up has been shown to reduce re-hospitalisation and improve patients' health $[50,51]$. Only two evaluations included videoconferencing as part of the telehealth intervention. QALYs might be more useful as an outcome measure in studies where the technology is used to provide new or additional services alongside traditional care rather than in studies where videoconferencing is used to replace conventional in-person consultations $[3,4]$.

Most studies originated in the Netherlands, the United Kingdom, the United States and Australia. This might be partially explained by extensive expertise in health economics and the focus on rigorous evaluations before the widespread adoption of any new health care technology or procedure.

The costing methodology has not been considered in detail in this review. However, most evaluations took a health provider and intervention cost perspective. Using the societal perspective in telehealth evaluation is important because it includes costs and benefits for all stakeholders involved, including patient costs associated with travel and treatment [1]. The costs and benefits form a range of different perspectives should be presented alongside a societal perspective [52]. 


\section{Preference measure and transparency of the QALY estimation}

All the reviewed evaluations used a pre-scored validated HRQoL instrument completed by patients to describe the health states. The evaluations followed accepted methods for transforming the quality scores into utility values. The EQ-5D was the most commonly used method. This coincides with other reviews of QALYs in the literature [53].

One important issue to consider when choosing a preference-based instrument is that each utility instrument is scored based on preferences from a particular population. HUI scores are based on residents of Canada. The EQ-5D and SF-6D use scores based on UK residents. These may not apply to other populations. Only one study used scores validated for a sub-group of the population (African-Americans) [33]. However, several studies have found that when measurements are replicated on different groups of people in different countries, the results are similar [9]. Furthermore, it has been acknowledged that patients tend to give a higher value to health states than the general population $[6,54]$. None of the reviewed evaluations asked the patients directly to value their health. Asking the patients directly may produce higher utility scores.

The reporting of utility scores at each point in time for each arm of the trial is important for the transparency of QALY estimation, so that the analysis can be replicated. Only half of the evaluations reported baseline and followup utility data separately. In most evaluation, it was also unclear whether differences in baseline utility data had been accounted for in the QALY estimation. This implies that the reported QALY gain in these studies can be misleading. Baseline utility is likely to correlate with QALYs and should be accounted for [9]. Manca et al. [55] argued that an imbalance in baseline utility needs to be adjusted regardless of whether these differences are formally statistically significant. They further argued that failure to control for this imbalance can result in misleading incremental cost-effectiveness ratios. Future economic evaluation in telehealth should be transparent in reporting utility data from all time points. They should also control for differences in baseline utility, whether or not these are significant.

Most evaluations reported the variability around the utility measure using relevant statistics. The reporting of the methodology of utility changes over time and the estimation of QALY gain, however, was less convincing. Transparency in reporting the methodology used to calculate QALYs is needed to ensure comparability across telehealth evaluations.

\section{Reporting of results}

The mean QALY gain varied from 0.001 to 0.118 in the reviewed evaluations implying a positive but small effect of telehealth on patient's health. Only six of these reported that the difference in QALYs were statistically significant. Half of the evaluations did not include a measure of variability around the utility values. Small positive QALY gains have also been found elsewhere. A recent economic evaluation of a large telehealth trial analysed the difference in QALYs for more than 900 patients. It found a small but not significant mean QALY gain of 0.012 [56].

The positive QALY improvements found in this review can contribute to the evidence supporting the claim that telehealth is at least as effective as usual care [57]. However, the absence of a negative QALY effect might be due to publication bias. It could also be because telehealth services with a negative impact have not yet been rigorously evaluated.

Small improvements in utility might not be considered clinically relevant. The minimally clinical important difference (MCID) is defined as the smallest difference in an outcome measure in the domain of interest that is perceived as beneficial [58]. It has been argued that the difference must be at least 0.03 in the utility score to be considered clinically meaningful [59-61]. It has also been demonstrated that the MCID differs between the EQ-5D and SF-6D [62]. Drummond (2001) argued that as long as the ultimate objective is to aid resource allocation decisions, it is the difference in incremental cost per QALY and not the improvement in utility that is important [59]. Most evaluations reviewed in this paper calculated the incremental cost per QALY even if the differences in utility were small and not significant. One of the reviewed evaluations found no significant difference in QALYs and costs but calculated that the telehealth service had a $62 \%$ probability of being cost-effective at a threshold of US\$50,000 USD [45] (see Table 1).

'No significant difference' does not necessarily mean an absence of difference [14]. It can be due to insufficient power, since most economic evaluations alongside trials have clinical measures as primary endpoints. It has also been argued that the difference between two sample means is a better estimate of effect difference than zero [9]. Even if some of the evaluations reported no significant differences in QALYs, none took a cost-minimisation approach. All except one [27] calculated incremental cost per QALY. This is in line with recommended methods. It has also been argued that, if telehealth is going to be adopted on a wider scale, it will have to estimate cost per QALY and pass the same rigorous tests on cost-effectiveness as other new health care interventions [63].

Costs and outcomes of interventions are always associated with some degree of uncertainty. Telehealth is associated with different services, contexts and local settings. Furthermore, parameters such as perspective, measurements, valuation and assumptions regarding cost and outcome identification may affect the results. Uncertainty may be due to sampling variation in cost and outcome 
data and non-sampling variation related to the economic model and the evaluation process [64]. Assessing uncertainty is important for the validity of the QALY estimation. In these reviewed papers, sampling variation was handled by reporting p-values and CIs for the utility measures. Most evaluations included CIs for the incremental cost per QALY ratio and a quarter illustrated CIs in the cost-effectiveness (CE) plane. To illustrate CIs graphically, cost-effect pairs are plotted in the CE plane, which shows the $95 \%$ confidence regions for the ratio [9]. Non-sampling variation is usually handled by sensitivity analyses, which was undertaken in less than half of the studies. This might limit the usefulness of the cost-effectiveness data found in this review as a basis for health care decision making.

Few evaluations in this review stated clear recommendations on the adoption of telehealth. The evaluations used a wide range of affordable thresholds for a QALY. Different countries accept different thresholds. For example, $£ 20,000-£ 30,000$ per QALY has been accepted as the threshold in the United Kingdom, US\$50,000-\$100,000 per QALY in the United States and AU\$76,000 in Australia [65]. Finland, Sweden, Denmark and Belgium do not suggest a threshold value [66]. There might also be differences in the potential value of threshold values for the cost per QALY between different health care systems [67]. These differences should be taken into account when cost-effectiveness results are compared between countries. In practice, whether to adopt new technology may depend on a wider set of objectives than simply to maximise health gain within the budget. These objectives can include the following: to address the lack of alternative treatment options, to reduce the net cost to the health provider, alleviate the burden of the disease, to enhance the innovative nature of the new technology and to address uncertainty regarding cost-effectiveness $[68,69]$.

\section{Challenges for the QALY approach in telehealth}

There are several limitations of using QALYs [70]. One is that the QALY approach does not capture all the benefits of health interventions. Disease-specific measures might capture more benefits than generic HRQoL measures. It has been argued that the EQ-5D and the SF-6D are too generic and insensitive to measure the main outcome of interest for less severe health problems [22,71]. When choosing a utility measure it is important to consider which method is most likely to be sensitive to the health change for the specific patient group included in the study. Disease-specific measures might be more sensitive to the health change that telehealth is likely to produce. Diseasespecific measures have been used to calculate QALYs in heart disease and cancer [72,73]. Researchers are working on developing instruments that try to measure broader outcomes within an economic evaluation framework [24].
The benefits of telehealth might extend beyond health outcomes such as access, information, waiting time, time saved and avoidance of burdensome travels. Therefore, for some telehealth interventions, a cost-benefit analysis using the willingness-to-pay approach might be more appropriate.

Another concern is that the QALY model uses different techniques to measure utilities and the results vary according to the method used. Different preference-based instruments can produce different utility values [71]. A number of studies have compared the performance of the SF-6D and the EQ-5D across conditions, settings and patient groups; most of these studies found poor agreement between the utility values [7,74-80]. These two systems vary in several aspects: The SF-6D has more dimensions and levels and explicitly include vitality and functioning. It uses standard gamble to derive utility measures, whereas EQ-5D uses the time-trade-off technique $[71,80]$. The EQ$5 \mathrm{D}$ tends to provide larger change scores and more favourable cost-effectiveness ratios than the SF-6D [77]. One of the reviewed studies used both the EQ-5D and the SF-6D and found positive cost per QALY results for only the EQ-5D utilities [29]. Another used the HUI3 in combination with the EQ-5D and found more QALYs gained using the HUI3 [33]. Ideally, all telehealth studies should use the same utility measure and method. Since different methods have been used in calculating QALYs, results across the telehealth studies should be compared with caution.

\section{Study limitations}

The main purpose of this review was to analyse the methodology and transparency of using QALYs in telehealth evaluations. The scope of this review is therefore quite narrow. Furthermore, excluding economic evaluations that synthesise secondary data in modelling studies is recognised as a limitation. Another limitation is that only articles written in English and published in peer-reviewed journals (to provide basic quality control) were included. In addition, the search strategy used might have overlooked some evaluations. The term 'telehealth' is not easily defined; some analysts might have used other terms and definitions to describe remote consultations and the provision of health care over a distance.

\section{Conclusion}

This paper provided a review of the methods used to calculate QALYs in telehealth evaluations. A total of 17 economic evaluations estimating QALYs were identified. All evaluations used validated HRQoL instruments to describe the health states. They also used accepted methods for transforming the quality scores into utility values. The evaluations differed in their choice of methods. Most evaluations reported the methodology used. The evaluations 
were less transparent in reporting the utility weights at different time points and the variability around utilities and QALYs. The different methods for estimating QALYs and the different threshold values for a QALY may affect the cost-effectiveness results and limit generalisability. It is therefore important to be transparent about the methodology used. Generalisability for telehealth research is problematic in general due to high diversity of technologies used, clinical fields and local health care settings. A more harmonised methodology and utility measure is needed to ensure comparability across telehealth evaluations.

\section{Competing interests}

The author declares no competing interests.

\section{Authors' contribution}

TSB is the sole author and responsible for conducting the review, analysing the articles and writing the manuscript.

\section{Acknowledgements}

I am grateful for the reviewers' valuable comments. This research was funded by a research grant from the regional health authority Helse Nord.

Received: 8 May 2013 Accepted: 21 July 2014

Published: 3 August 2014

\section{References}

1. Reardon T: Research findings and strategies for assessing telemedicine costs. Telemed J E Health 2005, 11(3):348-369.

2. Mistry $\mathrm{H}$ : Systematic review of studies of the cost-effectiveness of telemedicine and telecare. Changes in the economic evidence over twenty years. J Telemed Telecare 2012, 18(1):1-6.

3. Bergmo TS: Can economic evaluation in telemedicine be trusted? A systematic review of the literature. Cost Eff Resour Alloc 2009, 7:18.

4. Bergmo TS: Economic evaluation in telemedicine - still room for improvement J Telemed Telecare 2010, 16(5):229-231.

5. Sculpher MJ, Price M: Measuring costs and consequences in economic evaluation in asthma. Respir Med 2003, 97(5):508-520.

6. Maklin S, Rasanen P, Laitinen R, Kovanen N, Autti-Ramo I, Sintonen H, Roine RP: Quality-adjusted life-years for the estimation of effectiveness of screening programs: a systematic literature review. Int J Technol Assess Health Care 2012, 28(2):145-151.

7. Whitehurst DG, Bryan S, Lewis M: Systematic review and empirical comparison of contemporaneous EQ-5D and SF-6D group mean scores. Med Decis Making 2011, 31(6):E34-E44.

8. Soares MO: Is the QALY blind, deaf and dumb to equity? NICE's considerations over equity. Br Med Bull 2012, 101:17-31.

9. Drummond MF, Sculpher MJ, Torrance GW, O'Brien BJ, Stoddart GL: Methods for the Economic Evaluation of Health Care Programmes. 3rd edition. Oxford: Oxford University Press; 2005.

10. Olsen JA: Principles in Health Economics and Policy. Oxford: Oxford University Press; 2009.

11. Palmer S, Torgerson DJ: Economics notes: definitions of efficiency. BMJ: British Med J 1999, 318(7191):1136.

12. Ekeland AG, Bowes A, Flottorp S: Effectiveness of telemedicine: a systematic review of reviews. Int J Med Inform 2010, 79(11):736-771.

13. Wade VA, Karnon J, Elshaug AG, Hiller JE: A systematic review of economic analyses of telehealth services using real time video communication. BMC Health Serv Res 2010, 10:233.

14. Briggs $\mathrm{AH}, \mathrm{O}$ 'Brien $\mathrm{BJ}$ : The death of cost-minimization analysis? Health Econ 2001, 10(2):179-184.

15. EuroQol-Group: EuroQol-a new facility for the measurement of health-related quality of life. Health Policy 1990, 16:199-208.

16. NICE: Guide to the Method of Technology Appraisal. London: NICE; 2008

17. Brazier J, Roberts J, Deverill M: The estimation of a preference-based measure of health from the SF-36. J Health Econ 2002, 21(2):271-292.

18. Brazier JE, Roberts J: The estimation of a preference-based measure of health from the SF-12. Med Care 2004, 42(9):851-859.
19. Kaplan RM, Anderson JP: A general health policy model: update and applications. Health Serv Res 1988, 23(2):203-235.

20. Hawthorne G, Richardson J, Osborne R: The Assessment of Quality of Life (AQoL) instrument: a psychometric measure of health-related quality of life. Qual Life Res 1999, 8(3):209-224

21. Sintonen $\mathrm{H}$ : The $15 \mathrm{D}$ instrument of health-related quality of life: properties and applications. Ann Med 2001, 33(5):328-336.

22. Garau M, Shah KK, Mason AR, Wang Q, Towse A, Drummond MF: Using QALYs in cancer: a review of the methodological limitations. Pharmacoeconomics 2011, 29(8):673-685.

23. Cheung $\mathrm{K}$, Oemar M, Oppe M, Rabin R: EQ-5D user guide: basic information on how to use EQ-5D. Rotterdam: EuroQol Group; 2009.

24. Petrou S, Gray A: Economic evaluation alongside randomised controlled trials: design, conduct, analysis, and reporting. BMJ: British Med J 2011, 342:d1548.

25. Barnett TE, Chumbler NR, Vogel WB, Beyth RJ, Ryan P, Figueroa S: The cost-utility of a care coordination/home telehealth programme for veterans with diabetes. J Telemed Telecare 2007, 13(6):318-321.

26. Franzen C, Bjornstig U, Brulin C, Lindholm L: A cost-utility analysis of nursing intervention via telephone follow-up for injured road users. BMC Health Serv Res 2009, 9:98.

27. Moss-Morris R, McCrone P, Yardley L, van Kessel K, Wills G, Dennison L: A pilot randomised controlled trial of an Internet-based cognitive behavioural therapy self-management programme (MS Invigor8) for multiple sclerosis fatigue. Behav Res Ther 2012, 50(6):415-421.

28. Blankers M, Nabitz U, Smit F, Koeter MW, Schippers GM: Economic evaluation of internet-based interventions for harmful alcohol use alongside a pragmatic randomized controlled trial. J Med Int Res 2012, 14(5):e134

29. Willems DC, Joore MA, Hendriks JJ, Wouters EF, Severens JL: Cost-effectiveness of a nurse-led telemonitoring intervention based on peak expiratory flow measurements in asthmatics: results of a randomised controlled trial. Cost Eff Resour Alloc 2007, 5:10

30. Yardley L, Barker F, Muller I, Turner D, Kirby S, Mullee M, Morris A, Little P. Clinical and cost effectiveness of booklet based vestibular rehabilitation for chronic dizziness in primary care: single blind, parallel group, pragmatic, randomised controlled trial. BMJ 2012, 344:e2237.

31. Graves N, Barnett AG, Halton KA, Veerman JL, Winkler E, Owen N, Reeves MM, Marshall A, Eakin E: Cost-effectiveness of a telephone-delivered intervention for physical activity and diet. PLoS One 2009, 4(9):e7135.

32. Graves N, Courtney M, Edwards H, Chang A, Parker A, Finlayson K: Costeffectiveness of an intervention to reduce emergency re-admissions to hospital among older patients. PLoS One 2009, 4(10):e7455.

33. Hebert PL, Sisk JE, Wang JJ, Tuzzio L, Casabianca JM, Chassin MR, Horowitz C, McLaughlin MA: Cost-effectiveness of nurse-led disease management for heart failure in an ethnically diverse urban community. Ann Intern Med 2008, 149(8):540-548.

34. Pyne JM, Fortney JC, Tripathi SP, Maciejewski ML, Edlund MJ, Williams DK: Cost-effectiveness analysis of a rural telemedicine collaborative care intervention for depression. Arch Gen Psychiatry 2010, 67(8):812-821.

35. Smith B, Hughes-Cromwick PF, Forkner E, Galbreath AD: Cost-effectiveness of telephonic disease management in heart failure. Am J Manag Care 2008, 14(2):106-115.

36. Dolan P: NICE should value real experiences over hypothetical opinions. Nature 2009, 462(7269):35.

37. Lamers LM, McDonnell J, Stalmeier PF, Krabbe PF, Busschbach JJ: The Dutch tariff: results and arguments for an effective design for national EQ-5D valuation studies. Health Econ 2006, 15(10):1121-1132.

38. Lamers LM, Stalmeier PF, McDonnell J, Krabbe PF, van Busschbach JJ: [Measuring the quality of life in economic evaluations: the Dutch EQ-5D tariff]. Ned Tijdschr Geneeskd 2005, 149(28):1574-1578.

39. Gray AM, Rivero-Arias O, Clarke PM: Estimating the association between SF-12 responses and EQ-5D utility values by response mapping. Med Decis Making 2006, 26(1):18-29.

40. Brazier J, Roberts J, Deverill M: The estimation of a preference-based measure of health from the SF-36. J Health Econ 2002, 21(2):271-292.

41. Franks P, Lubetkin El, Gold MR, Tancredi DJ: Mapping the SF-12 to preference-based instruments: convergent validity in a low-income, minority population. Med Care 2003, 41(11):1277-1283.

42. Kimman ML, Dirksen CD, Voogd AC, Falger P, Gijsen BC, Thuring M, Lenssen $A$, van der Ent F, Verkeyn J, Haekens C, Hupperets $P$, Nuytinck JK, van Riet $Y$, Brenninkmeijer SJ, Scheijmans LJ, Kessels A, Lambin P, Boersma LJ: 
Economic evaluation of four follow-up strategies after curative treatment for breast cancer: results of an RCT. Eur J Cancer 2011, 47(8):1175-1185.

43. Neelemaat F, Bosmans JE, Thijs A, Seidell JC, van der Schueren MA VB-d: Oral nutritional support in malnourished elderly decreases functional limitations with no extra costs. Clin Nutr 2012, 31(2):183-190.

44. van Keulen HM, Bosmans JE, van Tulder MW, Severens JL, de Vries H, Brug J, Mesters I: Cost-effectiveness of tailored print communication, telephone motivational interviewing, and a combination of the two: results of an economic evaluation alongside the Vitalum randomized controlled trial. Int J Behav Nutr Phys Act 2010, 7:64.

45. van der Meer V, van den Hout WB, Bakker MJ, Rabe KF, Sterk PJ, Assendelft WJ, Kievit J, Sont JK: Cost-effectiveness of Internet-based self-management compared with usual care in asthma. PLoS One 2011, 6(11):e27108.

46. van Wier MF, Dekkers JC, Bosmans JE, Heymans MW, Hendriksen IJ, Pronk NP, van Mechelen W, van Tulder MW: Economic evaluation of a weight control program with e-mail and telephone counseling among overweight employees: a randomized controlled trial. Int J Behav Nutr Phys Act 2012, 9:112.

47. Handley MA, Shumway M, Schillinger D: Cost-effectiveness of automated telephone self-management support with nurse care management among patients with diabetes. Ann Fam Med 2008, 6(6):512-518.

48. Kepler CK, Wilkinson SM, Radcliff KE, Vaccaro AR, Anderson DG, Hilibrand AS, Albert TJ, Rihn JA: Cost-utility analysis in spine care: a systematic review. Spine J 2012, 12(8):676-690.

49. Tarride JE, Burke N, Bischof M, Hopkins RB, Goeree L, Campbell K, Xie F, O'Reilly D, Goeree R: A review of health utilities across conditions common in paediatric and adult populations. Health Qual Life Outcomes 2010, 8:12.

50. Yam CH, Wong EL, Chan FW, Wong FY, Leung MC, Yeoh EK: Measuring and preventing potentially avoidable hospital readmissions: a review of the literature. Hong Kong Med J 2010, 16(5):383-389.

51. Wu L, Forbes A, Griffiths P, Milligan P, While A: Telephone follow-up to improve glycaemic control in patients with Type 2 diabetes: systematic review and meta-analysis of controlled trials. Diabet Med 2010, 27(11):1217-1225.

52. Sculpher M, Pang F, Manca A, Drummond M, Golder S, Urdahl H, Davies L, Eastwood A: Generalisability in economic evaluation studies in healthcare: a review and case studies. Health Technol Assess 2004, 8(49):1-192.

53. Richardson G, Manca A: Calculation of quality adjusted life years in the published literature: a review of methodology and transparency. Health Econ 2004, 13(12):1203-1210.

54. Dolan P: Output Measures and Valuation in Health. Economic Evaluation in Health Care: Merging Theory with Practice; 2001:46-67.

55. Manca A, Hawkins N, Sculpher MJ: Estimating mean QALYs in trial-based cost-effectiveness analysis: the importance of controlling for baseline utility. Health Econ 2005, 14(5):487-496.

56. Henderson C, Knapp M, Fernández J-L, Beecham J, Hirani SP, Cartwright M, Rixon L, Beynon M, Rogers A, Bower P: Cost effectiveness of telehealth for patients with long term conditions (Whole Systems Demonstrator telehealth questionnaire study): nested economic evaluation in a pragmatic, cluster randomised controlled trial. BMJ: British Med J 2013, 346:f1035.

57. Cartwright M, Hirani SP, Rixon L, Beynon M, Doll H, Bower P, Bardsley M, Steventon A, Knapp M, Henderson C, Rogers A, Sanders C, Fitzpatrick R, Barlow J, Newman SP: Effect of telehealth on quality of life and psychological outcomes over 12 months (Whole Systems Demonstrator telehealth questionnaire study): nested study of patient reported outcomes in a pragmatic, cluster randomised controlled trial. BMJ 2013, 346:f653.

58. Jaeschke R, Singer J, Guyatt GH: Measurement of health status: ascertaining the minimal clinically important difference. Control Clin Trials 1989, 10(4):407-415.

59. Drummond $\mathrm{M}$ : Introducing economic and quality of life measurements into clinical studies. Ann Med 2001, 33(5):344-349.

60. Kaplan RM: The minimally clinically important difference in generic utility-based measures. COPD: J Chron Obstruct Pulmon Dis 2005, 2(1):91-97.

61. Walters SJ, Brazier JE: What is the relationship between the minimally important difference and health state utility values? The case of the SF-6D. Health Qual Life Outcomes 2003, 1(1):4.
62. Walters SJ, Brazier JE: Comparison of the minimally important difference for two health state utility measures: EQ-5D and SF-6D. Qual Life Res 2005, 14(6):1523-1532.

63. Wootton R: Twenty years of telemedicine in chronic disease management-an evidence synthesis. J Telemed Telecare 2012, 18(4):211-220

64. Briggs $A$ : Handling uncertainty in economic evaluation and presenting the results. In Economic Evaluation in Health Care: Merging Theory and Practice edn. Edited by Drummond M, McGuire A. Oxford: Oxford University Press; 2001.

65. Shiroiwa T, Sung YK, Fukuda T, Lang HC, Bae SC, Tsutani K: International survey on willingness-to-pay (WTP) for one additional QALY gained: what is the threshold of cost effectiveness? Health Econ 2010, 19(4):422-437.

66. Cleemput I, Neyt M, Thiry N, De Laet C, Leys M: Threshold Values for Cost-Effectiveness in Health Care. Belgian Health Care Knowledge Centre (KCE): Health Technology Assessment (HTA) Brussels; 2008.

67. Cleemput I, Neyt M, Thiry N, De Laet C, Leys M: Using threshold values for cost per quality-adjusted life-year gained in healthcare decisions. Int $J$ Technol Assess Health Care 2011, 27(1):71-76.

68. Devlin N, Parkin D: Does NICE have a cost-effectiveness threshold and what other factors influence its decisions? A binary choice analysis. Health Econ 2004, 13(5):437-452.

69. Culyer A, McCabe C, Briggs A, Claxton K, Buxton M, Akehurst R, Sculpher M, Brazier J: Searching for a threshold, not setting one: the role of the National Institute for Health and Clinical Excellence. J of health services Res \& policy 2007, 12(1):56-58.

70. Whitehead SJ, Ali S: Health outcomes in economic evaluation: the QALY and utilities. Br Med Bull 2010, 96:5-21.

71. Tinelli M, Ryan M, Bond C, Scott A: Valuing benefits to inform a clinical trial in pharmacy : do differences in utility measures at baseline affect the effectiveness of the intervention? Pharmacoeconomics 2013, 31(2):163-171.

72. Kontodimopoulos N, Aletras VH, Paliouras D, Niakas D: Mapping the cancer-specific EORTC QLQ-C30 to the preference-based EQ-5D, SF-6D, and 15D instruments. Value Health 2009, 12(8):1151-1157.

73. Wijeysundera HC, Tomlinson G, Norris CM, Ghali WA, Ko DT, Krahn MD Predicting EQ-5D utility scores from the Seattle angina questionnaire in coronary artery disease a mapping algorithm using a Bayesian framework. Med Decis Mak 2011, 31(3):481-493.

74. Conner-Spady B, Suarez-Almazor ME: Variation in the estimation of quality-adjusted life-years by different preference-based instruments. Med Care 2003, 41(7):791-801.

75. Barton GR, Sach TH, Avery AJ, Doherty M, Jenkinson C, Muir KR: Comparing the performance of the EQ-5D and SF-6D when measuring the benefits of alleviating knee pain. Cost Eff Resour Alloc 2009, 7:12.

76. Kontodimopoulos N, Pappa E, Papadopoulos AA, Tountas Y, Niakas D: Comparing SF-6D and EQ-5D utilities across groups differing in health status. Qual Life Res 2009, 18(1):87-97.

77. McDonough CM, Tosteson AN: Measuring preferences for cost-utility analysis: how choice of method may influence decision-making. Pharmacoeconomics 2007, 25(2):93-106.

78. Sach TH, Barton GR, Jenkinson C, Doherty M, Avery AJ, Muir KR: Comparing cost-utility estimates: does the choice of EQ-5D or SF-6D matter? Med Care 2009, 47(8):889-894.

79. Xie F, Li SC, Luo N, Lo NN, Yeo SJ, Yang KY, Fong KY, Thumboo J: Comparison of the EuroQol and short form 6D in Singapore multiethnic Asian knee osteoarthritis patients scheduled for total knee replacement. Arthritis Rheum 2007, 57(6):1043-1049.

80. Grieve R, Grishchenko M, Cairns J: SF-6D versus EQ-5D: reasons for differences in utility scores and impact on reported cost-utility. Eur J Health Econ 2009, 10(1):15-23.

doi:10.1186/1472-6963-14-332

Cite this article as: Bergmo: Using QALYs in telehealth evaluations: a systematic review of methodology and transparency. BMC Health Services Research 2014 14:332. 